\title{
CAN GRAPHENE BILAYERS BE THE MEMBRANE MIMETIC MATERIALS? ION CHANNELS IN GRAPHENE-BASED NANOSTRUCTURES
}

\section{Oleg V. Gradov}

Institute of Energy Problems of Chemical Physics, Russian Academy of Sciences, http://www.inepcp.ru 117829 Moscow, Russian Federation

gradov@chph.ras.ru

\section{Margaret A. Gradova}

Semenov Institute of Chemical Physics, Russian Academy of Sciences, http://www.chph.ras.ru 119991 Moscow, Russian Federation

Institute of Energy Problems of Chemical Physics, Russian Academy of Sciences, http://www.inepcp.ru

117829 Moscow, Russian Federation

gradova@chph.ras.ru

Abstract. The prospects of application of graphene and related structures as the membrane mimetic materials, capable of reproducing several biomembrane functions up to the certain limit, are analyzed in the series of our papers. This paper considers the possibility of the ion channel function modeling using graphene and its derivatives. The physical mechanisms providing selective permeability for different membrane mimetic materials, as well as the limits of the adequate simulation of the transport, catalytic, sensing and electrogenic properties of the cell membrane ion channels using bilayered graphene-based structures are discussed.

Keywords: ion channels, graphene, channel mimetics, nanopores, kapillarchemie, size-dependent electrochemistry, electric double-layer capacitor, ISFET \& ChemFET

PACS: 81.05.ue

Bibliography - 171 references

Received 14.11.2016

RENSIT, 2016, 8(2):154-170

DOI: $10.17725 /$ rensit.2016.08.154

\section{Contents}

1. INTRODUCTION (154)

2. Semipermeability AND the ION ChanNELS (154)

3. Pores and ion Channels in graphene-based NANOSTRUCTURES (158)

4. Conclusion (161)

REFERENCES (161)

\section{INTRODUCTION}

In [1] provides an overview of membrane models - semi-synthetic, synthetic, biogenic, semiconducting, superconducting, ferroelectric - and the related membrane mimetic materials from phospholipid bilayers and Langmuir films to multilayer nanofilms and ferromagnetic structures, along with the consideration of the problems of ambiguity models, completeness the membrane mimetic materials modeling, functional and substrate equivalence of the membrane mimetic materials. The use of analogical functional similarity criteria for the analysis of possibility of consideration of graphene, particularly the two-layer graphene as the membrane mimetic material - the subject of this work, with a focus on the analysis of it key property - permeability for ions, water and other organic matter.

\section{SEMIPERMEABILITY AND THE ION CHANNELS}

A well known flexibly adjustable semipermeability towards various agents is characteristic for the graphene-oxide membranes in organic solvents, with the size of the nanochannels providing either transport or blocking of several agents, which can be narrowed down by the thermal annealing or extended by solvation, thereby changing the boundary of the transmitted agent's size selectivity [2]. This corresponds to 
the well known models of the "size / solubility" - regulation of the sodium ion channels [3] and good approximations of the kinetic regimes depending on the ionic radius [4]. As a particular case of the applicability of the quantitative relations between the structure and biological activity (QSAR) [5], the analysis principles for the functional adjustability of the ion channels by the sink parameters, with the membrane pores corresponding to the drains, and the size of particles penetrating through those pores, in the case of the graphene layers fail to describe the membrane permeability, since the membrane considered performs a biological function despite the fact that its chemical composition is far from bioorganic one, and hence, is not included into the ion channel databases [6] which could be used to obtain QSAR data.

It is noteworthy that similar problems with the QSAR approaches earlier emerged in the analysis of the lipid nanopores operating as the ion channels of the cell membranes without any conventional ion channel components [7] due to their size corresponding to the ion radius. (Typically even at the dependence of the several ion channel group input on the ionic radius complex biochemical and crystallographic models are applied up to the homohexamer one [8], i.e. compatible with the QSAR principles based on the analysis of the conformation and steric accessibility of the channelome biomacromolecules).

In connection with the above contradiction it is also worth to mention the known data on the ionic permeability of the synthetic filters which have never been analyzed using QSAR methods for the similar reasons: it was shown that the ions penetrating through the synthetic PET filters are selected by the mechanisms providing the biomimetic and membrane mimetic kinetics with the discrete fast transitions between the conductivity levels and parametric selectivity of the ion fluxes, as well as inhibition by divalent cations, similar to the cell ion channels $[9,10]$.
Thus, it is possible to work out the criteria for verification of the biomimetic nature of the membrane mimetic models, based on the idea about the gradations of the ion channel efficiency according to the conductivity and bioelectric response generated, rather than on the conventional statement about the discrete transition between the excited states («all-ornone law» [11, 12]), typical for the deterministic model of the electrophysiological potential generation.

It is reasonable, since it has been shown earlier that the ion channel states (which are the prototypes of the membrane mimetic, or even channel mimetic models [13-15]) with a low ion conductivity in fact are not "closed", but are changing within several gradations providing qualitatively ("ion-selectively") and quantitatively (according to the permeability) distinguishable types of the membrane-electrophysical or electropysiological response, which is the main cause for the specific channelome noises at the patch-clamp registrograms [16]. Of course, this does not mean the close similarity between the biological and synthetic membrane structures or the possibility to reduce the channelome molecular machinery to the simple porous structure, but it indicates the general operation principles of the non-specific physical mechanisms at the nanoscale where the size effects are physically-determined and chemically-independent, i.e. are little if any influenced by the chemical composition of the medium and macromolecular morphology of the biopolymers (in a conventional meaning of this term introduced by P.J. Flory [17, 18], a Nobel prize winner and the author of the FloryHuggins equation which is formally similar to the Van der Waals equation, and hence, can be applied at the physical scale considered in this paper).

For the above reasons, biomimetic interpretation and assigning of the specific membrane properties to graphene and other layered membrane mimetic materials 
with the pore size corresponding to the ion radii, although does not contradict to the experimental data, in fact is a logical error of the inversion type, arising from the mixing of the deductive and inductive predicates: graphene and the cell membrane with the similar pore size obviously subject to the same physical and chemical principles (which is manifested in the similarity of the solvation regulation and the electrophysical response), and hence, in this aspect "graphene can be considered as a membrane mimetic material to the same extent as the biological membrane can be considered as a graphene-mimetic".

This suggests that the similarity problem (including the above mentioned QSAR) for such structures, if considered from the standpoint of molecular biology rather than biophysical and biocolloid chemistry, becomes incorrect. According to the classical colloid and capillary chemistry principles $[19,20]$ it is possible to determine the efficiency limits of the sorption processes within the pores and channels of the particular diameter, which is usually applied in cytophysiology [21] (the Freundlich adsorption isotherm [22] is named after Herbert Freundlich - the founder of the capillary chemistry and a pioneer of the capillary-chemical approaches in physiology). Thus, it is more appropriate to address the problem of channelomics of the graphene-oxide membrane mimetic materials from the standpoint of the size effects inherent to the former in the aspects of adsorption, filtration and size separation of the particles /ions, rather than in the framework of the specialized (supra)molecular structures which satisfy the similarity conditions to the specific cytophysiological structure performing the physical and chemical separation mechanism (i.e. "a similarity of the general phenomenon to its particular manifestation").

The effects of the size-dependent penetration of the chemical agents through the graphene layers are well known in nanochemistry [23, 24]. Reactivity towards different gases [25] and electrochemical properties of the nanoelectrode graphenelayers [25] also depend on the pore diameter. The above phenomenon known as "size-dependent electrochemistry" is a conceptual continuation of the Freundlich's "Kapillarchemie". This approach is widely applicable not only in the chemistry of the carbon structures, but also in the nanostructural materials science as a whole.

Regarding the carbon structures related to graphene, nanoelectrochemistry based on the size effects was applied in the studies on the multilayered carbon nanotubes [27] and a fully or partially reduced graphite oxide [28] which is an electrode material for electrochemical double-layer capacitors [29] often considered as the biological membrane bilayer model [3034], as well as the layered supercapacitors of EDLC-type ("electric double-layer capacitor") with the pronounced relation between the ion and pore sizes [35] similar to the biological membranes and membrane mimetic materials considered above. By the way, this is a reduced graphite oxide which is used as an electrode material in such supercapacitors [36], allowing the EDLC-based membrane models to mimic not only the energy storage function, but also a number of biochemical receptor functions, such as recognition and detection of the specific mediators/neurotransmitters/neurohormones (e.g. dopamine - [37-39]), performed on the basis of the electrochemical principles without any specific biomacromolecular agents [40-42] (in particular, due to the thickness-dependent hydrophobic properties of graphene, which is formally similar to the size-dependent properties of the "trans-graphene transport" of differently charged biomolecular agents through the pores in its hydrophobic surface $[43,44]$, which makes the problem of designing the graphene-based sensitive biomimetic materials soluble and similar to the design of the receptor mimetic peptides [45] based on the hydrophobic interaction simulations). 
To date, all the exceptions from this reductionistic rule, actually, confirm the rule, since the range of charge, mass and other physical and chemical parameters of the substances used in the composite techniques as well as the degrees of their biochemical (or immunochemical in the case of such detection principles) affinity differ by orders of magnitude: aptamers/nucleic acids [46, 47]; conductive polymers, such as polypyrrole (both at graphene and pyrolytic graphite) [48-51]; porphyrins and their derivaives, qualitatively different in their physical and chemical properties and aggregation behavior in solutions [52-54]; aminosugars - linear polysaccharide derivatives, such as chitosan [55, 56] used for immobilization; polymer electrolytic membranes, particularly those based on fluoride containing copolymers - fluorocarbon vinyl esters containing sulfonic groups (e.g. a well known nafion), including those with the composite impregnation by several inorganic components and structure-modifying agents [5760]; inorganic particles and clusters themselves gold, copper, nickel and zinc oxide nanoparticles [61-68]; graphene-doping chemical elements, such as nitrogen $[69,70]$. Although the above list is not complete, it fully represents the range of different mass and charge parameters for a number of molecules in the membrane mimetic structures performing receptor functions based on graphene and its derivatives. Despite the fact that in some cases electrophysical response has not been directly registered (detected only from the secondary indicators, such as redoxdependent fluorescence), the above information can be sufficient to prove by contradiction the correctness of the reductionistic model which does not require any bioorganic or macromolecular agents for performing the receptor functions by the membrane mimetic materials.

It is noteworthy that graphene-based nanostructures are often used in designing of both n-layered supercapacitors and sensors to various agents operating without enzymes
[71]. In such sensors graphene is only a kind of supercapacitor material - there are biosensors [72], gaze [73] and humidity [74] sensors (also capable of the energy storage) based on the non-graphene supercapacitor membrane coatings. Wherein, from the standpoint of the channelomics of such membrane mimetic materials, it should be mentioned that supercapacitor sensor membranes can separate ions, synthetic and biological molecules [75], promote dissociation of salts producing energy [76] due to the ion gradient (similar to the above cited Mitchell chemiosmotic model). Thus, energy supplying and sensing properties of the graphene-based membrane mimetic materials, which are phenomenologically similar to a number of fundamental properties inherent to the biomembranes, are provided by the electrophysical mechanisms (the molecule polarity, hydrophobicity and a number of properties related to the uncompensated charge interactions, in particular, coordination). It is not reasonable to consider the biosensor properties of the graphene-based membrane mimetic materials in this section, since they will be considered in details below, as well as the chemosensor ones, but the sensor properties of the supercapacitor-based membrane mimetic materials were discussed here for the reason of extrapolation of the ion channel- / membrane mimetic modeling criteria and the search for the general basis of the sensor, ionselective and electrophysical properties of the model system.

The aforementioned correlations between the electric and transport (ion-selective) properties require the example of their cooperative interaction. To date there are well known graphene-based ion-selective field-effect transistors (ISFET) sensitive to the proton concentration [77], which clearly correlates to the chemiosmotic model of the membrane electrogenesis, as well as with the model of biomembrane as the transistor structure known since 1960-th [78]. In such models the ion 
transport, sensing properties and changing of the sensor electric parameters are synchronized and interdependent. By the way, for all chemicallyselective field-effect transistors (ChemFET), and particularly for the ion-selective fieldeffect transistors (ISFET) [79, 80], there is no difference between the "membrane selectivity" and the "sensor electric response specificity" [81]. In recent years the ion sensing functions in microfluidic and even nanofluidic chemometric systems (labs-on-a-chip) are performed by the ionic transistors based on the ion concentration polarization by an ion exchange membrane [82], capable of performing electrogenic ion exchange and sensing with the electric response. Similar functions can be performed by the graphene or graphene oxide-based ion exchangers and composite ion-exchange materials [83-85], whereby the principles of synchronization of various aspects of their activity as multifunctional membrane mimetic materials can be realized using graphene and its analogs/derivatives applicable as FET. It should be noted that for performing of the most of the above mentioned functions graphenebased structures should posses only the FET properties, but not the whole ChemFET. There are sensors based on the graphene-containing FET structures (non-positioned as a ChemFET), but applied for the redox-sensing [86], aptasensing [87], electrochemical biosensing [88], metal ion sensing [89], as well as for design of the components of the bioelectronic "nose" [90]. This is due to the qualitative dependence of the graphene-based FET response on the ambient liquid and vapor media conditions [91], which may be due to the increased mobility of the charge carriers (holes), the decrease in the residual charge carrier concentration and changes in the molecular transport, induced by the charged defects (so-called perforation) near the surfaces of the active layers. The above effects result from the charge transport, as well as the molecule orientation induced by the charge near the FET surface [92], but it requires the presence of the vacant pores and charge defects in the membrane mimetic surface similar to the structural and electrophysiological features of biomembranes with the electrogenic properties, ionic transport and spatial molecule orientation in the controlling electric field are coupled and colocalized [93]).

\section{PORES AND ION CHANNELS IN GRAPHENE-BASED NANOSTRUCTURES}

Let us consider here the question about the presence of pores and the ion channel analogs (or the possibility of their realization) in graphene and its products, precursors and related compounds. There are known gazetransport [94] and ion-transport [95] channels in the laminar graphene oxide and graphenebased nanostructures of the electrophysical destination used in electrotechnics for designing of the lithium-ion batteries. All the phenomena of the selective ion penetration through the graphene structures are based on the above channel operation. In literature one can find the description of all kinds of the ion channels implemented on the basis of the graphene nanopores/nanochannels [96, 97]: for alkali metals [98], including biomimetic (bioinspired) analogs of the sodium and potassium channels [99] (as well as the other alkali metals, such as lithium, rubidium, and caesium [100-102], as follows from the thermodynamic calculations for the monovalent cations [103] and quantum chemical simulations for a number of the alkali metal ions [104], which can also operate in the channelome, but their clark is too low, and hence, does not allow to perform any significant functions at the macroscopic scale at the organism or the whole biosphere level), for the chloride ions [105] (the analogs of the known chloride ion channels [106, 107]), etc.

Consideration of the "exotic" pores and channels in graphene operating with the rubidium, gadolinium and other rare earth element ions $[108,109]$ is beyond the scope of 
this paper for the purpose of maintenance of the biomimetic functional analogy.

In the synthesis of the biomimetic graphenebased ISFET structures an important aspect is the compatibility with the channelome, since the carbon nanostructure-based ISFET are used in the electrophysical studies in neurocytology [110] by contact formation with the neurons, which serve as the ion-exchange structures between the channelome and FET, and are responsive to the extracellular medium and the mediated stimulation/inhibition of the iontransport channel activity [111]. Recent data on the possibility of the biomimetic ion channel function modeling and their introduction into the graphene capsules and membranelike structures, by 2015 made it possible to consider the graphene-based capsules with the ion-selective channels as the embryo protocells $[112,113]$. Though the above interpretation is doubtful, given that the early protocell models were actually simple phospholipid membrane structures [114-116], a membrane mimetic nature of this abstraction is clear, while it is not a breakthrough among the numerous non-lipid [117], membrane-free [118] and electrostaticallygated [119], inorganic [120, 121] mineral [122, 123] and other protocells, illustrating the recent tendency to the biomembrane substitution by its functional alternative.

However, it is evident that the synthetic functional model operates differently from its prototype, while providing chemical sensing in the vicinity of the graphene surfaces [124]: selective particle transport through the graphene layers can be performed accordingly not only to the particle charge or mass [125], but also to its spin [126], which is fundamentally different from the conventional physics of the biomembrane prototypes (although spin labels and other methods of the spin chemistry are often used in biophysics and cytophysiology for studying the ion channel properties and membrane permeability [127-131]). Thus, here we speak about the transduction of the physical agents rather than chemical (ionic) carriers of the QSPR/QSAR-coupled chemical parameters and physiological properties. In this case a model can be considered objective only if it is adequate to the biological prototype by the formation mechanism; functionally different models are based on different principles, and hence, reproduce the properties of the prototype only to the extent determined by the difference in their formation mechanisms.

There are known works on the graphene nanofluidic channel formation by scrolling graphene layers into a tube [132]. In biological systems there is an analogous example of the model channel formation via self-assembly (folding) of the cyclic peptide nanotubes [133] formed directly in the course of their interaction with the ligand [134] (as a supramolecular response [135] to the above interaction). Similarly occurs self-assembly of the model ion channel networks based on liquid-crystalline bicontinuous cubic phases [136] or columnar phases based on crown ethers in lipid bilayers [137]. The ion channel assembly from dendrimers is slightly different due to their branched structure [138], but this special case can not be implemented using graphene membrane mimetic structures, and hence, is beyond the scope of our paper. Another different mechanism of the membrane self-assembly, and hence, the membrane channel assembly, occurs under the templating conditions, which is simulated by the formation of the graphene films on various catalytic and ultramicrostructured surfaces (e.g. for obtaining FET and other ion-selective structures [139, 140]).

Catalytic structuring of the subsurface layer [141] is an inevitable condition for the on-surface synthesis. Templating on the inorganic catalytic surfaces is essential for the synthesis of a variety of inorganic catalytically-active (to a certain extent of self-assembly even autocatalyticallyactive) redox-surfaces [142]; similar requirements are in the synthesis of the layers with channels, mediated by the templating metal surfaces 
[143]. In such syntheses vacancies serve as the precursors (seeds) for the channel formation and are also involved in the determination and direction of the surface structuring forms under the phase transitions [144]. A similar but qualitatively opposite role is played by the metal ions: surfactant templating on the molten salt surfaces with the metal adducts leads to the formation of the metallotropic liquid-crystalline phases [145]. Given the applicability of the catalytic templating methods for the synthesis of the graphene-oxide nanostructures [146], it is possible to design graphene-based biomimetic /membrane mimetic surfaces with the ion channel function performed by the structures formed via templating and related mechanisms. This will correspond both to the templateassociated synthesis of the peptide ion channelmimicking systems [147] and to the formation of the synthetic inorganic transmembrane tubes and channels under the lipid templating [148], i.e. it will be substrate-independent from the biomolecular and supramolecular carriers, as well as from the organic/inorganic composition of the ion channel-mimicking structure as a whole, which is a prerequisite for the agent modeling of their functional mimetics.

Addressing the problem of catalysis in the ion channel mimetic self-assembly, including graphene-based structures, it is necessary to point out the catalytic function of the channelsprototypes. Catalytically-active are both cationic (e.g. calcium channels [149], characterized by the coupling of their catalytic and transport functions in the ATP-mediated $\mathrm{Ca}^{2+}$-transport), and anionic [150] ion channels and membrane ion pumps. Many specific regulators of the ion transport and permeability, such as CFTR - cystic fibrosis transmembrane conductance regulator [151, 152], catalytic and the channel opening/ closing regulation functions are also coupled. ATP-sensitive potassium channels (sometimes referred to as KATP/KATP or sarcKATP in sarcolemma, mitoKATP in chondriome, nucKATP at the nucleus depending on their localization), also possess catalytic activity [153, 154]. A similar situation occurs with the redoxregulators and the iron metabolism mediators ferritin-based ion channels [155], as well as with their synthetic derivatives and analogs made from nanostructures [156].

In general, synthetic catalytically-active pores [157] with the ion selectivity similar to their biological prototype are capable of performing the ion channel functions with the same (bio) catalytic function. The possibility of the above principle implementation using the agent models is determined by several conditions. Firstly, both for the potassium [158] and sodium [159] channels with the opposite operation modes (potassium channels are opened while the sodium ones are closed, since the cell resting potential parameters are close to the Nernst equilibrium potential of the potassium ions) catalysis plays an important role. Secondly, catalytic functions are characteristic both for the cationic and anionic channels (the term "chloride ion channels" in this case is not fully appropriate, since the same channels provide transport of the $\mathrm{HCO}_{3}{ }^{-}, \mathrm{I}^{-}$, $\mathrm{SCN}^{-}$and $\mathrm{NO}_{3}^{-}$anions). Thirdly, most of the model ion-selective systems are equally sensitive to most of the monovalent cations [160]. On the other hand, catalytic functions and the ligand recognition can be performed almost without any ion channels based on the pi-cation interactions [161]. At the same time coupling between the potential generation phases and catalytic cycles in the membrane can be provided by the lipids, e.g. by a phospholipid PI $(4,5) \mathrm{P} 2$ (phosphatidylinositol 4,5-bisphosphate) [162, 163]. Thus, the nature and structure of the agent itself are not significant for mimicking its function, while the adequate function reproduction is the key similarity criterion of the biomimetic model to its biological prototype.

Another characteristic example is the operation of the water channel associated with the catalytically-active sites [164] and their mimicking within the graphene layer or graphite surface in the form of the water transpiration 
channels $[165,166]$, which can be reproduced (with the presence of the driving gradient) beyond the structural modeling and design/ synthesis of the ion channel mimetics by means of the simple passive membrane model with its permeability dependent on the ion size, and water permeability within the same channels and the surface features [167]. This corresponds to the membrane pore model and the model of the non-selective independent ion channels with their permeability determined by the ion and molecule size. However, the native water channels - integral proteins aquaporins - also perform the pore functions, while some of them depending on the molecular size and shape also allow penetration of glycerin, ammonia, urea and carbon dioxide through the membrane [168].

\section{CONCLUSION}

In a general case, agent functional modeling of the ion channels using graphene-based structures is not only possible, but also satisfies the requirement for the colocalization of the ionselective and electrogenic functions, resulting from the analysis of the biophysical prototype (membrane) functions. Good examples of such structures with colocalization are the channels in the graphene-based ISFET - ion-selective fieldeffect transistors [169, 170] considered above. However, there are two aspects of electrogenesis, which can not be neglected during the analysis of the ion channel operation in graphene-based ISFET. One of them is the electrical double layer, which is the absolute theoretical limit of the nanoelectric system design, and the other one is the double layer nature of the biological membrane as a capacitor (which is required for modeling its periodical discharge in the form of the action and breakdown potentials in the area of the membrane pore formation), which should correspond to the double-layered structure of the graphene-based agent membrane mimetic material. Then the logic "performance" and the "duty cycle" of the graphene ion channel operation [171] in the electrogenic medium
- graphene bilayer - will possess a higher degree of similarity with its biological prototype. A detailed consideration of the electrical double layer as a driving force of the electrogenic processes and membrane mimetic structures, along with the consideration of the differences between the double-layered and multi-layered graphene-based structures and their single-layer analogs in the membrane mimetic aspect will be given in the next part of this paper.

\section{REFERENCES}

1. Gradov OV. Membrannye modeli i anzats dvukhsloynogo grafena kak membranomimetika [Can graphene bilayers be the membrane mimetic materials?]. Radioelektronika. Nanosistemy. Informatsionnye tekbnologii (RENSIT), 2016, 8(1):25-38 (in Russ.); DOI: 10.17725/rensit.2016.08.025.

2. Huang L, Li Y, Zhou Q, Yuan W, Shi G. Graphene Oxide Membranes with Tunable Semipermeability in Organic Solvents. $A d v$ Mater., 2015, 27(25):3797-3802.

3. Courtney KR. Sodium channel blockers: the size/solubility hypothesis revisited. Mol. Pharmacol., 1990, 37(6):855-859.

4. Courtney KR. Size-dependent kinetics associated with drug block of sodium current. Biophys. J., 1984, 45(1):42-44.

5. Courtney KR. Quantitative structure/activity relations based on use-dependent block and repriming kinetics in myocardium. J. Mol. Cell Cardiol., 1987, 19(3):319-330.

6. Le Novère N, Changeux JP. The Ligand Gated Ion Channel database: an example of a sequence database in neuroscience. Pbilos. Trans. R. Soc. Lond. B: Biol Sci., 2001, 356(1412):1121-1130.

7. Pakhomov AG, Bowman AM, Ibey BL, Andre FM, Pakhomova ON, Schoenbach KH. Lipid nanopores can form a stable, ion channel-like conduction pathway in cell membrane. Biochem. Biophys. Res. Commun., 2009, 385(2):181-186.

8. Cruickshank CC, Minchin RF, Le Dain AC, Martinac B. Estimation of the pore size of 
the large-conductance mechanosensitive ion channel of Escherichia coli. Biophys. J., 1997, 73(4):1925-1931.

9. Lev AA, Korchev YE, Rostovtseva TK, Bashford CL, Edmonds DT, Pasternak CA. Rapid switching of ion current in narrow pores: implications for biological ion channels. Proc. Biol. Sci., 1993, 252(1335):187-192.

10. Korchev YE, Bashford CL, Alder GM, Apel PY, Edmonds DT, Lev AA, Nandi K, Zima AV, Pasternak CA. A novel explanation for fluctuations of ion current through narrow pores. FASEB J., 1997, 11(7):600-608.

11. Osterhout WJ. Nature of the action current in nitella: V. Partial response and the all-ornone law. J. Gen. Physiol., 1943, 27(1):61-68.

12. Osterhout WJ. Apparent violations of the all-or-none law in relation to potassium in the protoplasm. J. Gen. Physiol., 1954, 37(6):813-824.

13. Steinle ED, Mitchell DT, Wirtz M, Lee SB, Young VY, Martin CR. Ion channel mimetic micropore and nanotube membrane sensors. Anal. Chem., 2002, 74(10):2416-2422.

14. Guo W1, Tian Y, Jiang L. Asymmetric ion transport through ion-channel-mimetic solid-state nanopores. Acc. Chem. Res., 2013, 46(12):2834-2846.

15. Wirtz M, Martin CR. Nanotube Membrane Sensors: Resistive Sensing and Ion Channel Mimetics. Sens. Upd., 2002, 11(1):35-64.

16. Korchev YE, Bashford CL, Alder GM, Kasianowicz JJ, Pasternak CA. Low conductance states of a single ion channel are not 'closed'. J. Membr. Biol., 1995, 147(3):233-239.

17. Flory PJ. Molecular morphology in amorphous and glass polymers. Journ. NonCrystal. Sol., 1980, 42(1-3):117.

18. Flory PJ, De Yeung Y. Molecular morphology in semicrystalline polymers. Nature, 1978, 272:226-229.

19. Freundlich H. Kapillarchemie; eine Darstellung der Chemie der kolloide und verwandter Gebiete, Band
1. Leipzig, Akademische Verlagsgesellschaft, 1930, 566 p.

20. Freundlich H. Colloid \& capillary chemistry. New York, E.P. Dutton \& Company, 1922, 883 p.

21. Freundlich H. Kapillarchemie und Physiologie. Dresden, Theodor Stienkopff, 1914, 48 p.

22. Freundlich H. Die Adsorption in Lösungen. Z. Phys. Chem., 1906, 57(A):385-470.

23. Plant SR, Cao L, Yin F, Wang ZW, Palmer RE. Size-dependent propagation of $\mathrm{Au}$ nanoclusters through few-layer graphene. Nanoscale, 2014, 6(3):1258-1263.

24. Jeon KJ, Lee Z. Size-dependent interaction of $\mathrm{Au}$ nanoparticles and graphene sheet. Chem. Commun., 2011, 47(12):3610-3612.

25. Si C, Zhou G. Size-dependent chemical reactivity of porous graphene for purification of exhaust gases. J. Chem. Phys., 2012, 137(18):184309-1-184309-6.

26. Zhang B, Fan L, Zhong H, Liu Y, Chen S. Graphene nanoelectrodes: fabrication and size-dependent electrochemistry. J. Am. Chem. Soc., 2013, 135(27):10073-10080.

27. Cardoso RM, Montes RH, Lima AP, Dornellas RM, Nossol E, Richter EM, Munoz RA. Multi-walled carbon nanotubes: Size-dependent electrochemistry of phenolic compounds. Electrochim. Acta, 2015, 176:36-43.

28. Tran MH, Yang CS, Yang S, Kim IJ, Jeong HK. Size dependent electrochemical properties of reduced graphite oxide. Chem. Phys. Lett., 2014, 608:207-212.

29. Hantel MM, Kaspar T, Nesper R, Wokaun A, Kötz R. Partially reduced graphite oxide as an electrode material for electrochemical double-layer capacitors. Chemistry, 2012, 18(29):9125-9136.

30. Rao S, Lu S, Guo Z, Li Y, Chen D, Xiang Y. A light-powered bio-capacitor with nanochannel modulation. Adv. Mater., 2014, 26(33):5846-5850. 
31. Lamport DT, Varnai P, Seal CE. Back to the future with the AGP-Ca ${ }^{2+}$ flux capacitor. Ann. Bot., 2014, 114(6):1069-1085.

32. Kim I, Warshel A. A Microscopic Capacitor Model of Voltage Coupling in Membrane Proteins: Gating Charge Fluctuations in CiVSD. J. Phys. Chem. B., 2016, 120(3):418-432.

33. Ray S, Kassan A, Busija AR, Rangamani $\mathrm{P}$, Patel HH. The plasma membrane as a capacitor for energy and metabolism. Am.J. Physiol. Cell Physiol., 2016, 310(3):C181-C192.

34. Gimsa J, Wachner D. A unified resistorcapacitor model for impedance, dielectrophoresis, electrorotation, and induced transmembrane potential. Biophys. J., 1998, 75(2):1107-1116.

35. Largeot C, Portet C, Chmiola J, Taberna PL, Gogotsi Y, Simon P. Relation between the ion size and pore size for an electric doublelayer capacitor. J. Am. Chem. Soc., 2008, 130(9):2730-2731.

36. Lobato B, Vretenár V, Kotrusz P, Hulman M, Centeno TA. Reduced graphite oxide in supercapacitor electrodes. J. Coll. Interf. Sci., 2015, 446:203-207.

37. Kannan PK, Moshkalev SA, Rout CS. Highly sensitive and selective electrochemical dopamine sensing properties of multilayer graphenenanobelts. Nanotechn., 2016, 27(7):075504-1-075504-9.

38. Qian T, Yu C, Wu S, Shen J. Gold nanoparticles coated polystyrene/reduced graphite oxide microspheres with improved dispersibility and electrical conductivity for dopamine detection. Coll. Surf. B: Biointerfaces, 2013, 112:310-314.

39. Qian T, Wu S, Shen J. Facilely prepared polypyrrole-reduced graphite oxide coreshell microspheres with high dispersibility for electrochemical detection of dopamine. Chem. Commun., 2013, 49(41):4610-4612.

40. Feng X, Zhang Y, Zhou J, Li Y, Chen S, Zhang L, Ma Y, Wang L, Yan X. Three-dimensional nitrogen-doped graphene as an ultrasensitive electrochemical sensor for the detection of dopamine. Nanoscale, 2015, 7(6):2427-2432.

41. Bagherzadeh M, Heydari M. Electrochemical detection of dopamine based on preconcentration by graphene nanosheets. Analyst, 2013, 138(20):6044-6051.

42. Cheemalapati S, Palanisamy S, Mani V, Chen SM. Simultaneous electrochemical determination of dopamine and paracetamol on multiwalled carbon nanotubes/graphene oxide nanocomposite-modified glassy carbon electrode. Talanta, 2013, 117:297-304.

43. Munz M, Giusca CE, Myers-Ward RL, Gaskill DK, Kazakova O. Thickness-Dependent Hydrophobicity of Epitaxial Graphene. ACS Nano., 2015, 9(8):8401-8411.

44. Schneider GF, Xu Q, Hage S, Luik S, Spoor JN, Malladi S, Zandbergen H, Dekker C. Tailoring the hydrophobicity of graphene for its use as nanopores for DNA translocation. Nat. Commun., 2013, 4:2619.

45. Martin-Moe SA, Lehr R, Cauley MD, Moe GR. Hydrophobic interactions and the design of receptor mimetic peptides. Pept. Res., 1995, 8(2):70-76.

46. Wang X, You Z, Sha H, Cheng Y, Zhu H, Sun W. Sensitive electrochemical detection of dopamine with a DNA/graphene bilayer modified carbon ionic liquid electrode. Talanta, 2014, 128:373-378.

47. Liu S, Xing X, Yu J, Lian W, Li J, Cui M, Huang J. A novel label-free electrochemical aptasensor based on graphene-polyaniline composite film fordopamine determination. Biosens. Bioelectron., 2012, 36(1):186-191.

48. Qian T, Yu C, Wu S, Shen J. In situ polymerization of highly dispersed polypyrrole on reduced graphite oxide for dopaminedetection. Biosens. Bioelectron., 2013, 50:157-160.

49. Qian T, Wu S, Shen J.Facilely prepared polypyrrole-reduced graphite oxide coreshell microspheres with high dispersibility for electrochemical detection of dopamine. Chem. Commun., 2013, 49(41):4610-4612. 
50. Si P, Chen H, Kannan P, Kim DH. Selective and sensitive determination of dopamine by composites of polypyrrole and graphenemodified electrodes. Analyst, 2011, 136(24):5134-5138.

51. Mao H, Liang J, Ji C, Zhang H, Pei Q, Zhang Y, Zhang Y, Hisaeda Y, Song XM. Poly(zwitterionic liquids) functionalized polypyrrole/graphene oxide nanosheets for electrochemically detecting dopamine at low concentration. Mater. Sci. Eng. C: Mater. Biol. Appl., 2016, 65:143-150.

52. Wu L, Feng L, Ren J, Qu X. Electrochemical detection of dopamine using porphyrinfunctionalized graphene. Biosens. Bioelectron., 2012, 34(1):57-62.

53. SakthinathanS,LeeHF,ChenSM, Tamizhdurai P. Electrocatalytic oxidation of dopamine based on non-covalent functionalization of manganese tetraphenylporphyrin/reduced graphene oxide nanocomposite. J. Coll. Interf. Sci., 2016, 468:120-127.

54. Yan X, Gu Y, Li C, Tang L, Zheng B, Li Y, Zhang Z, Yang M. Synergetic catalysis based on the proline tailed metalloporphyrin with graphene sheet as efficient mimetic enzyme for ultrasensitive electrochemical detection of dopamine. Biosens. Bioelectron., 2016, 77:1032-1038.

55. Niu X, Yang W, Guo H, Ren J, Yang F, Gao J. A novel and simple strategy for simultaneous determination of dopamine, uric acid and ascorbic acid based on the stacked graphene platelet nanofibers/ionic liquids/chitosan modified electrode. Talanta, 2012, 99:984-988.

56. Weng X, Cao Q, Liang L, Chen J, You C, Ruan Y, Lin H, Wu L. Simultaneous determination of dopamine and uric acid using layer-bylayer graphene and chitosan assembled multilayer films. Talanta, 2013, 117:359-365.

57. Ku S, Palanisamy S, Chen SM. Highly selective dopamine electrochemical sensor based on electrochemically pretreated graphite and nafion composite modified screen printed carbon electrode. J. Coll. Interf. Sci., 2013, 411:182-186.

58. Zhang W, Zheng J, Shi J, Lin Z, Huang Q, Zhang $\mathrm{H}$, Wei $\mathrm{C}$, Chen J, Hu S, Hao A. Nafion covered core-shell structured $\mathrm{Fe}_{3} \mathrm{O}_{4} @$ graphene nanospheres modified electrode for highly selective detection of dopamine. Anal. Chim. Acta., 2015, 853:285-290.

59. Liu CY, Liu ZY, Peng R, Zhong ZC. Quasireversible Process of Dopamine on Copper-Nickel Hydroxide Composite/ Nitrogen Doped Graphene/Nafion Modified GCE and Its Electrochemical Application. J. Anal. Meth. Chem., 2014, 2014:724538.

60. Ly SY, Park, Won D. Diagnosis of Dopamine in Brain Neuro Cell Using a Nafionimmobilized Carbon Electrode. Med. Chem., 2012, Sep 10. [Preprint].

61. Yang L, Huang N, Lu Q, Liu M, Li H, Zhang Y, Yao S. A quadruplet electrochemical platform for ultrasensitive and simultaneous detection of ascorbic acid,dopamine, uric acid and acetaminophen based on a ferrocene derivative functional $\mathrm{Au}$ NPs/carbon dots nanocomposite and graphene. Anal. Chim. Acta., 2016, 903:69-80.

62. Wang P, Xia M, Liang O, Sun K, Cipriano AF, Schroeder T, Liu H, Xie YH. Label-Free SERS Selective Detection of Dopamine and Serotonin Using Graphene-Au Nanopyramid Heterostructure. Anal. Chem., 2015, 87(20):10255-10261.

63. Li C, Zhao J, Yan X, Gu Y, Liu W, Tang L, Zheng B, Li Y, Chen R, Zhang Z. Tremellalike graphene-Au composites used for amperometric determination of dopamine. Analyst, 2015, 140(6):1913-1920.

64. Yan Y, Liu Q, Wang K, Jiang L, Yang X, Qian J, Dong X, Qiu B. Enhanced peroxydisulfate electrochemiluminescence for dopamine biosensing based on $\mathrm{Au}$ nanoparticle decorated reduced graphene oxide. Analyst, 2013, 138(23):7101-7106.

65. Chen X, Zhang G, Shi L, Pan S, Liu W, Pan H. Au/ZnO hybrid nanocatalysts 
impregnated in $\mathrm{N}$-doped graphene for simultaneous determination of ascorbic acid, acetaminophen and dopamine. Mater. Sci. Eng. C: Mater. Biol. Appl., 2016, 65:80-89.

66. He P, Wang W, Du L, Dong F, Deng Y, Zhang T. Zeolite A functionalized with copper nanoparticles and graphene oxide for simultaneous electrochemical determination of dopamine and ascorbic acid. Anal. Chim. Acta., 2012, 739:25-30.

67. Liu B, Ouyang X, Ding Y, Luo L, Xu D, Ning Y. Electrochemical preparation of nickel and copper oxides-decorated graphene composite for simultaneous determination of dopamine, acetaminophen and tryptophan. Talanta, 2016, 146:114-121.

68. Liu CY, Liu ZY, Peng R, Zhong ZC. Quasireversible Process of Dopamine on Copper-Nickel Hydroxide Composite/ Nitrogen DopedGraphene/Nafion Modified GCE and Its Electrochemical Application. J. Anal. Meth. Chem., 2014, 2014:724538.

69. Sheng ZH, Zheng XQ, Xu JY, Bao WJ, Wang FB, Xia XH. Electrochemical sensor based on nitrogen doped graphene: simultaneous determination of ascorbic acid, dopamine and uric acid. Biosens. Bioelectron., 2012, 34(1):125-131.

70. Thanh TD, Balamurugan J, Lee SH, Kim NH, Lee JH. Effective seed-assisted synthesis of gold nanoparticles anchored nitrogen-doped graphene for electrochemical detection of glucose and dopamine. Biosens. Bioelectron., 2016, 81:259-267.

71. Madhu R, Veeramani V, Chen SM, Manikandan A, Lo AY, Chueh YL. Honeycomb-like Porous CarbonCobalt Oxide Nanocomposite for HighPerformance Enzymeless Glucose Sensor and Supercapacitor Applications. ACS Appl. Mat. Interf., 2015, 7(29):15812-15820.

72. Mousty C, Leroux F. LDHs as electrode materials for electrochemical detection and energy storage: supercapacitor, battery and (bio)-sensor. Rec. Pat. Nanotech., 2012, 6(3):174-192.

73. Liu Y, Jiao Y, Zhang Z, Qu F, Umar A, Wu $\mathrm{X}$. Hierarchical $\mathrm{SnO}_{2}$ nanostructures made of intermingled ultrathin nanosheets for environmental remediation, smart gas sensor, and supercapacitor applications. ACS Appl. Mat. Interf., 2014, 6(3):2174-2184.

74. Must I, Johanson U, Kaasik F, Põldsalu I, Punning A, Aabloo A. Charging a supercapacitor-like laminate with ambient moisture: from a humidity sensor to an energy harvester. Phys. Chem. Chem. Phys., 2013, 15(24):9605-9614.

75. Meng JP, Gong Y, Lin Q, Zhang MM, Zhang P, Shi HF, Lin JH. Metal-organic frameworks based on rigid ligands as separator membranes in supercapacitor. Dalton Trans., 2015, 44(12):5407-5416.

76. Sales BB, Saakes M, Post JW, Buisman CJ, Biesheuvel PM, Hamelers HV. Direct power production from a water salinity difference in a membrane-modified supercapacitor flow cell. Envir. Sci. Technol., 2010, 44(14):5661-5665.

77. Kiani MJ, Ahmadi MT, Karimi Feiz Abadi H, Rahmani M, Hashim A, Che Harun FK. Analytical modelling of monolayer graphenebased ion-sensitive FET to $\mathrm{pH}$ changes. Nanoscale Res. Lett., 2013, 8(1):173-1-173-9.

78. Johnson RN, Hanna GR. Membrane model: a single transistor analog of excitable membrane. J. Theor. Biol., 1969, 22(3):401-411.

79. Sibbald A, Covington AK, Carter RF. Simultaneous on-line measurement of blood $\mathrm{K}^{+}, \mathrm{Ca}^{2+}, \mathrm{Na}^{+}$, and $\mathrm{pH}$ with a four-function ChemFET integrated-circuit sensor. Clin. Chem., 1984, 30(1):135-137.

80. Sibbald A, Covington AK, Carter RF. Online patient-monitoring system for the simultaneous analysis of blood $\mathrm{K}^{+}, \mathrm{Ca}^{2+}$, $\mathrm{Na}^{+}$and $\mathrm{pH}$ using a quadruple-function ChemFET integrated-circuit sensor. Med. Biol. Eng. Comput., 1985, 23(4):329-338.

81. Costa J, Fernandes M, Vieira M, Lavareda G, Karmali A. Membrane selectivity versus 
sensor response in hydrogenated amorphous silicon ChemFETs using a semi-empirical model. J. Nanosci. Nanotechnol., 2011, 11(10):8844-8847.

82. Sun G, Senapati S, Chang HC. High-flux ionic diodes, ionic transistors and ionic amplifiers based on external ion concentration polarization by an ion exchange membrane: a new scalable ionic circuit platform. Lab Chip., 2016, 16(7):1171-1177.

83. Mo Y, Wan Y, Chau A, Huang F. Graphene/ Ionic liquid composite films and ion exchange. Sci. Rep., 2014, 4:5466-1-5466-8.

84. Chen G, ZhaiS,Zhai Y,Zhang K, Yue Q, Wang L, Zhao J, Wang H, Liu J, Jia J. Preparation of sulfonic-functionalized graphene oxide as ion-exchange material and its application into electrochemiluminescence analysis. Biosens. Bioelectron., 2011, 26(7):3136-3141.

85. Zhang S, Shao Y, Liu J, Aksay IA, Lin Y. Graphene-polypyrrole nanocomposite as a highly efficient and low cost electrically switched ion exchanger for removing $\mathrm{ClO}_{4}^{-}$ from wastewater. ACS Appl. Mat. Interf., 2011, 3(9):3633-3637.

86. Park JW, Park SJ, Kwon OS, Lee C, Jang J. Polypyrrole nanotube embedded reduced graphene oxide transducer for field-effect transistor-type $\mathrm{H}_{2} \mathrm{O}_{2}$ biosensor. Anal. Chem., 2014, 86(3):1822-1828.

87. Kwon OS, Park SJ, Hong JY, Han AR, Lee JS, Lee JS, Oh JH, Jang J. Flexible FETtype VEGF aptasensor based on nitrogendoped graphene converted from conducting polymer. ACS Nano, 2012, 6(2):1486-1493.

88. Farid S, Meshik X, Choi M, Mukherjee S, Lan Y, Parikh D, Poduri S, Baterdene U, Huang CE, Wang YY, Burke P, Dutta M, Stroscio MA. Detection of Interferon gamma using graphene and aptamer based FET-like electrochemical biosensor. Biosens. Bioelectron., 2015, 71:294-299.

89. Park JW, Park SJ, Kwon OS, Lee C, Jang J. High-performance $\mathrm{Hg}^{2+}$ FETtype sensors based on reduced graphene oxide-polyfuran nanohybrids. Analyst, 2014, 139(16):3852-3855.

90. Park SJ, Kwon OS, Lee SH, Song HS, Park TH, Jang J. Ultrasensitive flexible graphene based field-effect transistor (FET)-type bioelectronic nose. Nano Lett., 2012, 12(10):5082-5090.

91. Worley BC, Kim S, Park S, Rossky PJ, Akinwande D, Dodabalapur A. Dramatic vapor-phase modulation of the characteristics of graphene field-effect transistors. Phys. Chem. Chem. Phys., 2015, 17(28):18426-18430.

92. Min M, Seo S, Lee J, Lee SM, Hwang E, Lee $H$. Changes in major charge transport by molecular spatial orientation in graphene channel field effect transistors. Chem. Commun., 2013, 49(56):6289-6291.

93. Strejčková A, Staničová J, Jancura D, Miškovský P, Bánó G. Spatial orientation and electric-field-driven transport of hypericin inside of bilayer lipid membranes. J. Phys. Chem. B., 2013, 117(5):1280-1286.

94. Shen J, Liu G, Huang K, Jin W, Lee KR, $\mathrm{Xu}$ N. Membranes with fast and selective gas-transport channels of laminar graphene oxide for efficient $\mathrm{CO}_{2}$ capture. Angew. Chem. Int. Ed. Engl., 2015, 54(2):578-582.

95. Chen XC, Wei W, Lv W, Su FY, He YB, Li B, Kang F, Yang QH. A graphene-based nanostructure with expanded ion transport channels for high rate Li-ion batteries. Chem. Commun., 2012, 48(47):5904-5906.

96. Sun P, Zhu M, Wang K, Zhong M, Wei J, Wu $\mathrm{D}, \mathrm{Xu}$ Z, Zhu H. Selective ion penetration of graphene oxide membranes. ACS Nano, 2013, 7(1):428-437.

97. Sint K, Wang B, Král P. Selective ion passage through functionalized graphene nanopores. J. Am. Chem. Soc., 2008, 130(49):16448-16449.

98. Boukhvalov DW, Virojanadara C. Penetration of alkali atoms throughout a graphene membrane: theoretical modeling. Nanoscale, 2012, 4(5):1749-1753.

99. He Z, Zhou J, Lu X, Corry B. Bioinspired graphene nanopores with voltage-tunable 
ion selectivity for $\mathrm{Na}^{+}$and $\mathrm{K}^{+}$. ACS Nano, 2013, 7(11):10148-10157.

100. Grahame-Smith DG, Wang H. Comparison of the actions of lithium, rubidium, and caesium on rat brain 5-HT function: pharmacological implications of ion channel function. Clin. Neuropharmacol., 1992, 15(Suppl. 1):614A-615A.

101. Boccaccio A, Conti F, Olivera BM, Terlau

H. Binding of kappa-conotoxin PVIIA to Shaker $\mathrm{K}^{+}$channels reveals different $\mathrm{K}^{+}$and $\mathrm{Rb}^{+}$occupancies within the ion channel pore. J. Gen. Physiol., 2004, 124(1):71-81.

102. Mao G, Winokur MJ, Karasz FE. Dual alkali-metal-ion channel structures in poly(pphenylenevinylene). Phys. Rev. B: Cond. Matt., 1996, 53(2):R463-R467.

103. Miller C, Stahl N, Barrol M. A thermodynamic analysis of monovalent cation permeation through a $\mathrm{K}^{+}$-selective ion channel. Neuron, 1988, 1(2):159-164.

104. Billes F, Mohammed-Ziegler I, Mikosch H. Transportation behavior of alkali ions through a cell membrane ion channel. A quantum chemical description of a simplified isolated model. J. Mol. Model., 2012, 18(8):3627-3637.

105. Hilder TA, Gordon D, Chung SH. Synthetic chloride-selective carbon nanotubes examined by using molecular and stochastic dynamics. Biophys. J., 2010, 99(6):1734-1742.

106. Middleton RE, Pheasant DJ, Miller C. Homodimeric architecture of a $\mathrm{ClC}$ type chloride ion channel. Nature, 1996, 383(6598):337-340.

107. Li Y, Yeo GF, Milne RK, Madsen BW, Edeson RO. Burst properties of a supergated double-barrelled chloride ion channel. Math. Biosci., 2000, 166(1):23-44.

108. Franco A, Winegar BD, Lansman JB. Open channel block by gadolinium ion of the stretch-inactivated ion channel in $\mathrm{mdx}$ myotubes. Biophys. J., 1991, 59(6):1164-1170.

109. Wang K, McIlvain B, Tseng E, Kowal D, Jow F, Shen R, Zhang H, Shan QJ, He
L, Chen D, Lu Q, Dunlop J. Validation of an atomic absorption rubidium ion efflux assay for KCNQ/M-channels using the ion Channel Reader 8000. Assay Drug Dev. Technol., 2004, 2(5):525-534.

110. Massobrio G, Massobrio P, Martinoia S. Modeling the neuron-carbon nanotubeISFET junction to investigate the electrophysiological neuronal activity. Nano Lett., 2008, 8(12):4433-4440.

111. Martinoia S, Massobrio P. ISFET-neuron junction: circuit models and extracellular signal simulations. Biosens. Bioelectron., 2004, 19(11):1487-1496.

112. Li Z, Wang C, Tian L, Bai J, Yao H, Zhao Y, Zhang X, Cao S, Qi W, Wang S, Shi K, Xu Y, Mingliang Z, Liu B, Qiu H, Liu J, Wu W, Wang X, Wenzhen A. An embryo of protocells: The capsule of graphene with selective ion channels. Sci. Rep., 2015, 5:10258-1-10258-14.

113. Li Z, Wang C, Tian L, Bai J, Yao H, Zhao Y, Zhang X, Cao S, Qi W, Wang S, Shi K, Xu Y, Mingliang Z, Liu B, Qiu H, Liu J, Wu W, Wang X, Wenzhen A. Corrigendum: An embryo of protocells: The capsule of graphene with selective ion channels. Sci. Rep., 2015, 5:12386.

114. Stillwell W. Facilitated diffusion as a method for selective accumulation of materials from the primordial oceans by a lipid-vesicle protocell. Orig. Life., 1980, 10(3):277-292.

115. Liu J, Stace-Naughton A, Jiang X, Brinker CJ. Porous nanoparticle supported lipid bilayers (protocells) as delivery vehicles. J. Am. Chem. Soc., 2009, 131(4):1354-1355.

116. Walde P. Building artificial cells and protocell models: experimental approaches with lipid vesicles. Bioessays, 2010, 32(4):296-303.

117. Li M, Huang X, Tang TY, Mann S. Synthetic cellularity based on non-lipid micro-compartments and protocell models. Curr. Opin. Chem. Biol., 2014, 22:1-11. 
118. Koga S, Williams DS, Perriman AW, Mann S. Peptide-nucleotide microdroplets as a step towards a membrane-free protocell model. Nat. Chem., 2011, 3(9):720-724.

119. Li M, Harbron RL, Weaver JV, Binks BP, Mann S. Electrostatically gated membrane permeability in inorganic protocells. Nat. Chem., 2013, 5(6):529-536.

120. Cooper GJ, Kitson PJ, Winter R, Zagnoni M, Long DL, Cronin L. Modular redox-active inorganic chemical cells: iCHELLs. Angew. Chem. Int. Ed. Engl., 2011, 50(44):10373-10376.

121. Kumar RK, Li M, Olof SN, Patil AJ, Mann S. Artificial cytoskeletal structures within enzymatically active bio-inorganic protocells. Small, 2013, 9(3):357-362.

122. Gupta VK. Emergence of photoautotrophic minimal protocell-like supramolecular assemblies, "Jeewanu" synthesied photo chemically in an irradiated sterilised aqueous mixture of some inorganic and organic substances. Orig. Life Evol. Biosph., 2014, 44(4):351-355.

123. Kaur G, Rath G, Heer H, Goyal AK. Optimization of protocell of silica nanoparticles using $3^{2}$ factorial designs. AAPS PharmSciTech., 2012, 13(1):167-173.

124. Yasaei P, Kumar B, Hantehzadeh R, Kayyalha M, Baskin A, Repnin N, Wang C, Klie RF, Chen YP, Král P, Salehi-Khojin A. Chemical sensing with switchable transport channels in grapheme grain boundaries. Nat. Commun., 2014, 5:4911.

125. Rickhaus P, Liu MH, Makk P, Maurand R, Hess S, Zihlmann S, Weiss M, Richter K, Schönenberger C. Guiding of Electrons in a Few-Mode Ballistic Graphene Channel. Nano Lett., 2015, 15(9):5819-5825.

126. Cantele G, Lee YS, Ninno D, Marzari N. Spin channels in functionalized graphene nanoribbons. Nano Lett., 2009, 9(10):3425-3429.

127. Archer SJ, Ellena JF, Cafiso DS. Dynamics and aggregation of the peptide ion channel alamethicin. Measurements using spin-labeled peptides. Biophys. J., 1991, 60(2):389-398.

128. Perozo E, Cuello LG, Cortes DM, Liu YS, Sompornpisut P. EPR approaches to ion channel structure and function. Novartis Found Symp., 2002, 245:146-168.

129. Holt SA, Le Brun AP, Majkrzak CF, McGillivray DJ, Heinrich F, Lösche M, Lakey JH. An ion-channel-containing model membrane: structural determination by magnetic contrast neutron reflectometry. Soft Matter, 2009, 5(13):2576-2586.

130. Endeward B, Butterwick JA, Mackinnon R, Prisner TF. Pulsed electron-electron double-resonance determination of spinlabel distances and orientations on the tetrameric potassium ion channel KcsA. J. Am. Chem. Soc., 2009, 131(42):15246-15250.

131. Dellisanti CD, Ghosh B, Hanson SM, Raspanti JM, Grant VA, Diarra GM, Schuh AM, Satyshur K, Klug CS, Czajkowski C. Site-directed spin labeling reveals pentameric ligand-gated ion channel gating motions. PLoS Biol., 2013, 11(11):e1001714, 1-14.

132. Mirsaidov U, Mokkapati VR, Bhattacharya D, Andersen H, Bosman M, Özyilmaz B, Matsudaira P. Scrolling graphene into nanofluidic channels. Lab Chip, 2013, 13(15):2874-2878.

133. Montenegro J, Ghadiri MR, Granja JR. Ion channel models based on self-assembling cyclic peptide nanotubes. Acc. Chem. Res., 2013, 46(12):2955-2965.

134. Mayer M, Semetey V, Gitlin I, Yang J, Whitesides GM. Using ion channelforming peptides to quantify proteinligand interactions. J. Am. Chem. Soc., 2008, 130(4):1453-1465.

135. Sánchez-Quesada J, Isler MP, Ghadiri MR. Modulating ion channel properties of transmembrane peptide nanotubes through heteromeric supramolecular assemblies. J. Am. Chem. Soc., 2002, 124(34):10004-10005. 
136. Ichikawa T, Yoshio M, Hamasaki A, Mukai T, Ohno H, Kato T. Self-organization of room-temperature ionic liquids exhibiting liquid-crystalline bicontinuous cubic phases: formation of nano-ion channel networks. J. Am. Chem. Soc., 2007, 129(35):10662-10663.

137. Cazacu A, Tong C, van der Lee A, Fyles TM, Barboiu M. Columnar self-assembled ureido crown ethers: an example of ionchannel organization in lipid bilayers. J. Am. Chem. Soc., 2006, 128(29):9541-9548.

138. Nyitrai G, Keszthelyi T, Bóta A, Simon A, Tőke O, Horváth G, Pál I, Kardos J, Héja L. Sodium selective ion channel formation in living cell membranes by polyamidoamine dendrimer. Biochim. Biophys. Acta., 2013, 1828(8):1873-1880.

139. Abhilash TS, De Alba R, Zhelev N, Craighead HG, Parpia JM. Transfer printing of CVD graphene FETs on patterned substrates. Nanoscale, 2015, 7(33):14109-14113.

140. Ping J, Wang Y, Ying Y, Wu J. Application of electrochemically reduced graphene oxide on screen-printed ion-selective electrode. Anal. Chem., 2012, 84(7):3473-3479.

141. Lukas M, Meded V, Vijayaraghavan A, Song L, Ajayan PM, Fink K, Wenzel W, Krupke R. Catalytic subsurface etching of nanoscale channels in graphite. Nat. Commun., 2013; 4:1379.

142. Choi BS, Kim SM, Gong J, Lee YW, Kang SW, Lee HS, Park JY, Han SW. One-pot self-templating synthesis of $\mathrm{Pt}$ hollow nanostructures and their catalytic properties for CO oxidation. Chemistry, 2014, 20(37):11669-11674.

143. Yang F, Zhou S, Wang H, Long S, Liu $\mathrm{X}$, Kong Y. A metal-assisted templating route $\left(\mathrm{S}^{0} \mathrm{M}^{+} \mathrm{I}^{-}\right)$for fabricating thin-layer $\mathrm{CoO}$ covered on the channel of nanosphericalHMS with improved catalytic properties. Dalton Trans., 2016, 45(15):6371-6382.

144. Li Y, Guijarro N, Zhang X, Prévot MS, Jeanbourquin XA, Sivula $K$, Chen H, Li Y. Templating Sol-Gel Hematite
Films with Sacrificial Copper Oxide: Enhancing Photoanode Performance with Nanostructure and Oxygen Vacancies. ACS Appl. Mat. Interf., 2015, 7(31):16999-17007.

145. Martin JD, Keary CL, Thornton TA, Novotnak MP, Knutson JW, Folmer JC. Metallotropic liquid crystals formed by surfactant templating of molten metal halides. Nat. Mater., 2006, 5(4):271-275.

146. Moon GH, Shin Y, Choi D, Arey BW, Exarhos GJ, Wang C, Choi W, Liu J. Catalytic templating approaches for threedimensional hollow carbon/graphene oxide nano-architectures. Nanoscale, 2013, 5(14):6291-6296.

147. Chaloin L, Méry J, Van Mau N, Divita G, Heitz F. Synthesis of a template-associated peptide designed as a transmembrane ion channel former. J. Pept. Sci., 1999, 5(9):381-391.

148. Wang Y, Ma S, Su Y, Han X. Palladium nanotubes formed by lipid tubule templating and theirapplicationinethanolelectrocatalysis. Chemistry, 2015, 21(16):6084-6089.

149. Inesi G, Kirtley ME. Coupling of catalytic and channel function in the $\mathrm{Ca}^{2+}$ transport ATPase. J. Membr. Biol., 1990, 116(1):1-8.

150. Hsu CM, Rosen BP. Characterization of the catalytic subunit of an anion pump. J. Biol. Chem., 1989, 264(29):17349-17354.

151. Ramjeesingh M, Li C, Garami E, Huan LJ, Galley K, Wang Y, Bear CE. Walker mutations reveal loose relationship between catalytic and channel-gating activities of purified CFTR (cystic fibrosis transmembrane conductance regulator). Biochemistry, 1999, 38(5):1463-1468.

152. Csanády L, Vergani P, Gadsby DC. Strict coupling between CFTR's catalytic cycle and gating of its $\mathrm{Cl}^{-}$ion pore revealed by distributions of open channel burst durations. Proc. Nat. Acad. Sci. USA, 2010, 107(3):1241-1246.

153. Bienengraeber M, Alekseev AE, Abraham MR, Carrasco AJ, Moreau C, Vivaudou M, 
Dzeja PP, Terzic A. ATPase activity of the sulfonylurea receptor: a catalytic function for the KATP channel complex. FASEB J., 2000, 14(13):1943-1952.

154. Park S, Lim BB, Perez-Terzic C, Mer G, Terzic A. Interaction of asymmetric ABCC9encoded nucleotide binding domains determines KATP channel SUR2A catalytic activity. J. Proteome Res., 2008, 7(4):1721-1728.

155. Behera RK, Theil EC. Moving $\mathrm{Fe}^{2+}$ from ferritin ion channels to catalytic $\mathrm{OH}$ centers depends on conserved protein cage carboxylates. Proc. Nat. Acad. Sci. USA, 2014, 111(22):7925-7930.

156. Theil EC. Ferritin protein nanocages use ion channels, catalytic sites, and nucleation channels to manage iron/oxygen chemistry. Curr. Opin. Chem. Biol., 2011, 15(2):304-311.

157. Sakai N, Sordé N, Matile S. Synthetic catalytic pores. J. Am. Chem. Soc., 2003, 125(26):7776-7777.

158. Sharma V, Wikström M. The role of the $\mathrm{K}$-channel and the active-site tyrosine in the catalytic mechanism of cytochrome c oxidase. Biochim. Biophys. Acta., 2016, 1857(8):1111-1115.

159. Chakrabarti N, Ing C, Payandeh J, Zheng $\mathrm{N}$, Catterall WA, Pomès R. Catalysis of $\mathrm{Na}^{+}$ permeation in the bacterial sodium channel $\mathrm{Na}(\mathrm{V})$ Ab. Proc. Nat. Acad. Sci. USA, 2013, 110(28):11331-11336.

160. Lim C, Dudev T. Potassium Versus

Sodium Selectivity in Monovalent Ion Channel Selectivity Filters. Met. Ions Life Sci., 2016, 16:325-347.

161. Zacharias N, Dougherty DA. Cation-pi interactions in ligand recognition and catalysis. Trends Pharmacol Sci., 2002, 23(6):281-287.

162. Okamura Y. Lipids: PI couples voltage to catalysis. Nat. Chem. Biol., 2010, 6(5):315-316.

163. Kohout SC, Bell SC, Liu L, Xu Q, Minor DL, Isacoff EY. Electrochemical coupling in the voltage-dependent phosphatase Ci-VSP. Nat. Chem. Biol., 2010, 6(5):369-375.
164. Dhindwal S, Priyadarshini P, Patil DN, Tapas S, Kumar P, Tomar S, Kumar P. Ligandbound structures of 3-deoxy-D-mannooctulosonate 8-phosphate phosphatase from Moraxella catarrhalis reveal a water channel connecting to the active site for the second step of catalysis. Acta Crystallogr. D: Biol. Crystallogr., 2015, 71(2):239-255.

165. Marti J, Nagy G, Gordillo MC, Guàrdia E. Molecular simulation of liquid water confined inside graphite channels: thermodynamics and structural properties. J. Chem. Phys., 2006, 124(9):94703-1-94703-7.

166. Thekkethala JF, Sathian SP. Thermal transpiration through single walled carbon nanotubes and graphene channels. J. Chem. Phys., 2013, 139(17):174712-1-174712-9.

167. Leung SS, Sindhikara D, Jacobson MP. Simple Predictive Models of Passive Membrane Permeability Incorporating SizeDependent Membrane-Water Partition. J. Chem. Inf. Model., 2016, 56(5):924-929.

168. Kreida S, Törnroth-Horsefield S. Structural insights into aquaporin selectivity and regulation. Curr. Opin. Struct. Biol., 2015, 33:126-134.

169. Jang M, Trung TQ, Jung JH, Kim BY, Lee NE. Improved performance and stability of field-effect transistors with polymeric residue-free graphene channel transferred by gold layer. Phys. Chem. Chem. Phys., 2014, 16(9):4098-4105.

170. Ramesh P, Itkis ME, Bekyarova E, Wang F, Niyogi S, Chi X, Berger C, de Heer W, Haddon RC. Electro-oxidized epitaxial graphene channel field-effect transistors with single-walled carbon nanotube thin film gate electrode. J. Am. Chem. Soc., 2010, 132(41):14429-14436.

171. Li SL, Miyazaki H, Hiura H, Liu C, Tsukagoshi K. Enhanced logic performance with semiconducting bilayer graphene channels. ACS Nano, 2011, 5(1):500-506. 